\title{
Effects of the $A^{y}$ substitution on mouse activity level: Spurious pleiotropy'
}

\author{
JAMES D. HAWKINS \\ CLAREMONT GRADUATE SCHOOL
}

\begin{abstract}
Inbred mice of four genotypes were tested over a 165-min. period in an activity apparatus. The data support the conclusion that obesity, principally determined by a single gene substitution, can account for about one-half of the variance in activity scores when compared with a normal body-weight group. The interpretation considers the remaining variance which is also of genetic origin and argues for the study of stable behavioral phenotypes in tracting gene-behavior pathways via the non-congruent model of gene action.
\end{abstract}

\section{Problem}

The basic assumption in this study was: Animals differing in anatomy and/or physiology of known genetic causation can be useful in the study of gene-behavior pathways. The history and rationale for such work has been surveyed by Thiessen (1965a).

Hereditary effects on rodent activity scores have long been recognized (Rundquist, 1933) as have the effects of obesity (Richter, 1958). It was expected that a marked activity decrement would accompany gross obesity attributable to a substitution at a single gene locus. However, it was further recognized that even when one starts with such a known physical characteristic, likely to be of behavioral importance, and with the principle genetic determination known, interpretations might be tentative because of genetic interaction and pleiotropy.

\section{Subjects}

The Ss were C57BL/6J mice maintained with forced heterozygosis at the locus of interest. Specifically, all of the animals carried the Non agouti (black) gene $a_{i}$ The alleles which assorted at random were $a$ and $A^{y}$ (yellow lethal) from the agouti series on linkage group V. The black animals (genotype aa) represented 67 generations of brother/sister mating. The Jackson Laboratory stock to which they can be traced are F64. The yellow mice $\left(A^{y} a\right)$ had been backcrossed in this subline 22 or more generations.

Ten animals of each sex, from each color variety were used. All were experimentally naive. The weight range between color varieties was completely discontinuous at testing. For each subgroup it was (in grams): male $A^{y_{a}}$, 48.6-39.4; female $A^{y_{a}}$, 41.3-31.1; male $a a$, 28.0-24.8; female $a a, 25.9-19.6$.

\section{Apparatus}

The exploratory maze was made of plywood and had over-all dimensions of 1 by 4 by $4 \mathrm{ft}$. Sixteen compartments were contained within this enclosure; each $1 \mathrm{ft}$ square and $1 \mathrm{ft}$ deep. Four in square openings in the partitions separating the compartments allowed un- obstructed movement from one to another. Treadles (2-1/2 by 4 in) built into the floor at the openings were constructed so as to close electrical circuits when depressed. A lead from each of these circuits extended to an Esterline-Angus Operations Recorder. A Telechron electric timer was connected to the recorder to provide time samples in the data.

\section{Procedure}

After being weaned at 30 days, each animal was kept in a separate galvanized steel cage ( 6 by 6 by 12 in) with water and Purina Lab Chow ad libitum. Routine care procedures consisted of replenishing the food and water supply daily and transferring the animals to clean cages weekly. All illumination was artificial and a 12 hr. dark/light cycle was maintained. Temperature variation was between 72 and 78 degrees fahrenheit during the course of the experiment.

In testing, each animal was released in the maze and given one, uninterrupted, 165-min. trial. The mice were weighed to the nearest decigram and run in the apparatus at 125 days of age (+ or -2 days). All trials were carried out under normal room illumination and during the light portion of the animal's usual dark/light cycle.

\section{Results}

The number of compartment entries for each $\mathrm{S}$ in each of six 5-min. periods was transcribed from the records and subjected to an analysis of variance. The activity differences associated with the agouti locus is highly significant $(F=60.28, \mathrm{df}=1 / 36, \mathrm{p}<.001)$ while sex chromosome effects do not reach the .05 confidence level. The color by sex interaction is also nonsignificant, indicating that these alleles have similar activity effects with both sex chromosome backgrounds.

An analysis of covariance between color varieties was carried out in which the effects of the weight differences between these groups was removed statistically. The square root transformation of Freeman and Tukey (Edwards, 1960) was applied to make the group regression lines parallel. The activity differences between color varieties is still highly significant, though the obtained $F$ is greatly reduced $(F=10.38, d f=1 / 37)$. A Pearson $r$ computed from these data was .696. The square of this value indicates the proportion of the variance in activity which can be accounted for by the body-weight data (i.e., 48\%).

\section{Discussion}

This study indicates that a single gene, $A^{y}$, which has pleiotropic structural effects, e.g., increased fat deposition, skeletal enlargement, linear size increase 
(Gruneberg, 1943), also affects the amount of exploratory activity exhibited by $\mathrm{C} 57 \mathrm{BL} / 6 \mathrm{~J}$ mice. According to Gruneberg, in genuine pleiotropy a single gene controls two or more different traits which it produces directly by the use of different mechanisms. In spurious pleiotropy the gene does two or more things directly through the same mechanism or else has one effect which causes other things to happen. While it is not precluded by these results, genuine pleiotropy is not demonstrated. Spurious pleiotropy is shown to exist since the statistical analysis indicates that obesity is a basic mediator of the activity differences between groups.

Of further interest are the activity differences remaining after allowance for differences between groups in obesity. These differences must also have a genetic basis since genotype at the agouti locus and sex chromosome constitution are the only independent variables in the study. The mechanism through which $A^{y}$ has this action is undetermined. It can be seen, however, that for this activity measure the $A^{y}$ substitution does not interact with the total gene complement since significant color by sex differences are not found.

Hirsch has argued cogently for recognition of the inherent genetic diversity which must exist in all populations, even those which are inbred (e.g., Hirsch. 1962, 1964). Several studies in the literature, and now this one, report single gene substitutions which produce marked behavioral changes. Yet, in a review paper, Thiessen (1965b) shows that despite a multiplicity of investigators, experimental techniques, and testing devices, the several sublines of the C57 strain have produced a stable phenotype with regard to activity measures over many years. Since numerous single gene differences can be assumed among the various sublines of a strain, such stability might not be expected. A rational explanation is provided by the noncongruent model of gene action which has as its basic premises: "Single genes characteristically affect many forms of behavior; single psychological traits have variance ascribable to many genes"' (Fuller \& Thompson, 1960). The theorists go on, however, to postulate that a given behavior may be insensitive to a good nortion of the metabolic shunting within the physiolos.ca $\mathrm{pr}^{\mathrm{c}}$. is lying between the genotype and the behavioral phenotype. This is likely the basis for such well buffered behavior systems as Thiessen describes. Certain major-gene substitutions, such as $A^{y}$, are able to disrupt such systems and produce behavior differences within a strain of the order normally found between strains.

Where major-gene substitutions produce behavioral changes in an otherwise well buffered system, more refined analysis of genetically controlled behavior mechanisms becomes plausible because both physiological and behavioral changes are referable to a single genetic source. The consideration of genuine and spurious pleiotropy in such research provides direct evidence concerning the postulated non-congruence of genotype, physiological substrate, and behavioral phenotype.

\section{References}

Edwards, A. L. Experimental design in psychological research. New York: Holt, Rinehart \& Winston, 1960.

Fuller, J. L., \& Thompson, W. R.. Behavior genetics. New York: Wiley, 1960

Grueneberg. H. The genetics of the mouse. Cambridge: University Press, 1943

Hirsch, J. Individual differences in behavior and their genetic basis In E. Bliss, (Ed), Roots of behavior. New York: Harper, 1962

Hirsch, J. Breeding analysis of natural units in behavior genetics. Amer. Zoologist, 1964, 4, 139-145.

Richter, C P. Neurological basis of responses to stress. In G. E Wolstenholme (Ed.), Neurological basis of behavior. Boston: Little-Brown, 1958

Rundquist, E. A. The inheritance of spontaneous activity in rats. J. comp. Psychol., 1933, 16, 415-438.

Thiessen, D..D. The wabbler-lethal mouse: A study in development. Anim. Behav., 1965a. 13, 87-100.

Tniessen, D. D. Persistent genotypic differences in mouse activity under unusually varied circumstances. Psychon. Sci., 1965b, $3,1-2$.

\section{Note}

1. This report was partially supported by Research Fellowship MH 16,374 from the National Institute of Mental Health, U. S. Public Health Service. 